\title{
UN SAN JOSÉ ATRIBUIDO AL ESCULTOR FRANCISCO ANTONIO GIJÓN
}

\author{
A SAINT JOSEPH ATTRIBUTED TO THE SCULPTOR \\ FRANCISCO ANTONIO GIJÓN
}

\author{
José RodA PEÑA \\ Universidad de Sevilla. España \\ roda@us.es
}

\begin{abstract}
Estudio de una talla en madera policromada y pequeño formato de San José, perteneciente a una colección particular sevillana, que tras el pertinente examen de sus rasgos técnicos, estilísticos e iconográficos, proponemos su atribución a Francisco Antonio Gijón (1653-c. 1705), uno de los grandes maestros de la escultura barroca andaluza.

Palabras claves: San José, Francisco Antonio Gijón, Sevilla, escultura barroca, siglo XVII.
\end{abstract}

Study of a carving in polychrome wood and small format of Saint Joseph, belonging to a particular sevillian collection, that after the pertinent examination of its technical, stylistic and iconographic characteristics, we propose its attribution to Francisco Antonio Gijón (1653-c. 1705), one of the big masters of the baroque andalusian sculpture.

Keywords: Saint Joseph, Francisco Antonio Gijón, Seville, baroque sculpture, 17 $7^{\text {th }}$ century.

El pasado año 2011, los propietarios del prestigioso establecimiento de joyería Casa Ruiz de Sevilla, fundado en 1928, adquirieron para su colección particular una interesante escultura en madera policromada y pequeño formato de San José (56 cm de alto), cuyo anterior poseedor nada pudo señalarles acerca de su procedencia ${ }^{1}$. Como quiera que la pieza mostraba un deficiente estado de conservación, enseguida se tomó la determinación de restaurarla, encomendando su

${ }^{1}$ Agradezco sinceramente a mis buenos amigos de Joyería Casa Ruiz: D. Ricardo Roldán Barbero, D. Rafael Ruiz Gálvez, D. Ignacio Joaquín Ruiz García, D. Joaquín Roldán Ruiz y D. Alejandro Joaquín Ruiz Núñez, las facilidades que me han otorgado para estudiar esta escultura de su propiedad, así como el informe emitido a consecuencia de su restauración. 
intervención a Manuel Antonio Ruiz-Berdejo Cansino. En este sentido, cabe resaltar que la imagen llegó a su taller con puntuales mermas en el soporte lígneo, caso de varias falanges de los dedos de las manos y de algunos trozos en la zona posterior del manto; además, había perdido su ojo derecho de cristal, apreciándose asimismo la rotura de los dos pies por su parte frontal. De otro lado, la película pictórica se presentaba con la habitual acumulación de suciedad superficial y oxidación de su barniz, siendo más graves los repintes detectados en la túnica del santo, así como ciertas lagunas y falta de adhesión de los distintos estratos a la madera. Todas estas patologías fueron subsanadas durante el proceso restaurador, empleando materiales reversibles en lo referente al revestimiento cromático, utilizándose pasta de madera para reconstruir los fragmentos faltantes de talla y reponiéndose el extraviado globo ocular vítreo. También se tomó la determinación de encargar al escultor Luciano Galán García (Utrera, 1973) la ejecución de un Niño Jesús de nueva factura, en barro cocido y policromado, pues el San José había llegado a la actualidad sin esta figura infantil que sin duda tuvo en origen, como lo delata la posición de sus manos en ademán de sostenerlo acunado. La peana sobre la que descansa la obra, de madera tallada y decorada con gallones -dorados y rojos, alternativamente-, no es la primitiva, pero encaja estéticamente bien con el conjunto, por lo que ha resultado plausible su mantenimiento.

Una vez que se me ofreció la oportunidad de poder estudiar con detenimiento esta imagen de San José, pude percatarme que su peculiar técnica de talla y sus caracteres estilísticos y morfológicos vinculaban su factura al quehacer del afamado escultor utrerano Francisco Antonio Gijón (1653-c. 1705)², una atribución contrastada con el parecer de otros colegas que también tuvieron ocasión de contemplar la efigie ${ }^{3}$ y que ahora me propongo sostener con argumentos que le otorguen suficiente firmeza.

De inmediato debe traerse a colación la similitud compositiva e iconográfica que muestra este San José con respecto a la escultura de la misma temática pero superior envergadura (1,26 m) que le fue encomendada a Gijón en 1678 por parte de la Hermandad Sacramental de la parroquia hispalense de San Nicolás ${ }^{4}$,

${ }^{2}$ Tras el pionero trabajo de HERNÁNDEZ DÍAZ, José: "Notas para un estudio biográfico-crítico del escultor Francisco Antonio Gijón”, Revista Universitaria, 1, 1930 , pp. 1-22, se han publicado las siguientes monografías sobre este artista: BERNALES BALLESTEROS, Jorge: Francisco Antonio Gijón. Sevilla, 1982; RODA PEÑA, José: Francisco Antonio Ruiz Gijón, escultor utrerano. Utrera, 2003, y DÁVILA-ARMERO DEL ARENAL, Álvaro; PÉREZ MORALES, José Carlos y LÓPEZ-FE Y FIGUEROA, Carlos María: Francisco Antonio Ruiz Gijón. Sevilla, 2010.

3 Valoro especialmente el criterio del profesor Alfonso Pleguezuelo, quien comparte lo pertinente de esta atribución a Francisco Antonio Gijón.

${ }^{4}$ Este encargo a Gijón, por el que se le pagaron 1.004 reales, fue documentado por FALCÓN MÁRQUEZ, Teodoro: "La iglesia de San Nicolás de Bari, de Sevilla", Archivo Hispalense, 147-152, 1968, pp. 191-192. Sobre el contenido artístico de la capilla 
donde se conserva presidiendo el retablo de la cabecera de la nave colateral de la epístola más cercana a la capilla mayor del templo. En efecto, en ambos casos el patriarca bendito adelanta y gira hacia adentro la pierna izquierda, contundente movimiento que se acusa en el drapeado de la túnica, sobre todo a la altura de la rodilla, dejando al descubierto el correspondiente pie calzado con sandalia; no obstante, la actitud itinerante está más plenamente lograda en el San José de Casa Ruiz, cuya apariencia resulta, en general, más dinámica, a lo que también contribuye el vuelo adquirido por el manto, replegado en amplias y profundas ondas en torno al brazo izquierdo y recogido por la cara interna del derecho, liberando prácticamente la visión del frente de la figura, que así la percibimos como más estilizada y grácil que su homónima de San Nicolás. La disposición del juego de manos es bastante parecida en los dos ejemplos: vueltas hacia el lado izquierdo -en rotación inversa a la ya descrita para la pierna que avanza-, la siniestra algo más elevada que su contraria, con las palmas abiertas para mantener entre ellas al pequeño Jesús. Sí percibo entre los dos San José una diferencia en el plano gestual, que a mi entender afecta al mensaje y contenido expresivo que tratan de transmitir. En el de San Nicolás, el semidesnudo y mofletudo Niño Dios es mostrado por su padre terrenal como para ser objeto de adoración por parte del espectador, y a este último es a quien el santo dirige su invitadora mirada; sin embargo, en la escultura que ahora damos a conocer, y a pesar de la desgraciada carencia de la imagencita infantil -suplida, como expusimos, por otra de reciente hechura-, la afectuosa comunicación paterno-filial la juzgo más evidente, como lo pone de manifiesto la inclinación del rostro del patriarca, que tiende sus ojos hacia el cuerpecillo de Jesús.

Estas dos versiones suponen una reinterpretación -más barroquizada desde el punto de vista formal- del modelo iconográfico propuesto por Pedro Roldán en 1664 en su San José de la catedral de Sevilla; pero si en este vemos al Niño Jesús descansar sobre un blanco pañal entre las manos de su amado protector, formando todo el grupo un bloque compacto de talla, Francisco Antonio Gijón, en cambio, prefirió concebir estos dos infantillos como imágenes sobrepuestas y extraíbles, probablemente para facilitar que pudieran sobrevestirse con fajas o túnicas de tejido natural, aunque con la fatídica consecuencia del extravío de uno de ellos, el de Casa Ruiz.

La definición formal de los finos rasgos faciales y la intensidad expresiva que se reflejan en el rostro de este San José que analizamos contribuyen a cimentar su atribución a Gijón, sobre todo cuando se evidencian los paralelismos con otras fisonomías plasmadas por el maestro utrerano en esculturas de un tamaño similar o incluso inferior a este. Descendiendo al detalle, la particularísima tipología

dedicada a San José en esta parroquia, véase FALCÓN MÁRQUEZ, Teodoro: La Iglesia de San Nicolás de Bari de Sevilla. Una iglesia del siglo XIII en un templo barroco. Sevilla, 2008, pp. 66-68 y 99. 
y naturaleza material de los almendrados ojos de cristal, así como el modo de insertarlos en la mascarilla, constituyen una nota distintiva de su autor, que encontramos, por ejemplo, en la amplia panoplia de criaturas angélicas que pueblan las andas procesionales que este artífice talló para diversas cofradías penitenciales de Sevilla, recordándome su juvenil semblante - prescindiendo, naturalmente, de su bigote y barba- al de algunos ángeles, niños y mancebos, de los que decoran el paso del Gran Poder (1688-1692) y aún más si cabe, a la pareja de seres alados recientemente recuperada del desaparecido canasto del Nazareno de las Tres Caídas de la parroquia de San Isidoro $(1687)^{5}$, con los que también comparte este San José el codificado recurso de entreabrir los labios para manifestar una emoción anhelante, siendo incluso posible divisar, en su contemplación cercana, la arcada dentaria superior. En el tratamiento grumoso y compacto de los cabellos -tan común entre los escultores sevillanos de la segunda mitad del siglo XVII-, que se despliegan por la espalda del santo describiendo un amplio abanico de largos, sinuosos y bien perfilados mechones de puntas rizadas, no se despega Gijón de una práctica habitual a la hora de trabajar el pelo en algunas de sus esculturas masculinas, como el Cristo de la Expiración de Triana (El Cachorro), el Nazareno de la parroquia de Nuestra Señora de los Ángeles de Los Santos de Maimona o el evangelista San Juan del paso del Crucificado de la cofradía hispalense del Museo.

En una de las cláusulas del testamento otorgado por Francisco Antonio Gijón el 10 de noviembre de 1693 ante el escribano público Jacinto de Medina, declara "que yo tengo hecho un San José con su Niño a Antonio de Castro, y lo ajusté con el susodicho en cuatrocientos reales de vellón, y me tiene dado a cuenta cien reales" ${ }^{\prime}$. Pone en evidencia que dicha escultura estaba concluida para tal fecha, aunque no terminada de pagar por parte del comitente, ese tal Antonio de Castro. Su precio podría resultar indicativo de tratarse de una imagen de talla completa y formato más o menos reducido, tan adecuado para destinarse a la devoción privada y quizás a un ámbito de contemplación doméstico, aunque ello no deje de ser una mera especulación, puesto que se desconoce ningún otro detalle fehaciente sobre su hechura, destino inicial o paradero actual, aunque sea tentador relacionarla con el San José que ocupa nuestra atención, una posibilidad que en absoluto puede desecharse.

Pero aún me resulta más sugerente la hipótesis de su factible identificación con la escultura realizada por "Francisco Jijón" del "San José que está sobre un Trono de Ángeles, en el Altar de la Resurrección de dicha Capilla [de la Expiración]". Hemos extraído esta cita de la Memoria de la Pintura, i Excultura singular

${ }^{5}$ RODA PEÑA, José: "Dos ángeles de Francisco Antonio Gijón en la Cofradía de las Tres Caídas de San Isidoro”, Boletín de las Cofradías de Sevilla, 601, 2009, pp. 196-197.

${ }^{6}$ CUÉLLAR CONTRERAS, Francisco de Paula: "Testamento del maestro escultor Francisco Antonio Gijón”, Boletín de las Cofradías de Sevilla, 185, 1975, p. 14. 
que ai en este Real Convento Cassa Grande, del Real, i Militar Orden de Nuestra Señora de la Merced Redempción de Cauptibos, de la Ciudad de Sevilla, manuscrito firmado y fechado el 27 de mayo de 1730 por fray Pedro Vázquez que se custodia en el Archivo de la Curia Provincial de la Merced de Castilla en Madrid, y del que se conservan dos copias (1732 y 1789) en la Biblioteca Capitular y Colombina de Sevilla ${ }^{7}$. El autor de la Memoria, al adentrarse en la capilla de la Hermandad del Cristo de la Expiración, situada otrora en el compás del convento casa grande de la Merced Calzada (actual Museo de Bellas Artes) y hoy anexa al mismo, repara, en lo que a escultura se refiere, en el Crucificado de pasta modelado por Marcos de Cabrera en 1575 -que él adjudica a un "Clérigo Criollo"- y en un conjunto de efigies esculpidas por Gijón para la mencionada cofradía de penitencia: "La Imagen de los Dolores, los cuatro Evangelistas y todos los Ángeles, que salen en el paso la Semana Santa", además del ya citado San José que se acomodaba en el altar de la Resurrección de Cristo, el célebre lienzo pintado por Bartolomé Esteban Murillo hacia 1650-1655, arrebatado de su emplazamiento original en 1810 y devuelto a España por el gobierno francés en 1814, cuando ingresó en la Real Academia de Bellas Artes de San Fernando de Madrid?.

En el interior de la capilla del Cristo de la Expiración se tiene constancia documental de la existencia de ese retablo de "Nuestro Señor Resucitado y Patriarca Señor San José”, al menos desde junio de 1698, cuando diversas escrituras notariales indican que debía servir de modelo para el que pretendía erigirse en el muro frontero de dicho recinto sagrado ${ }^{10}$. Recordemos que la Memoria se refiere

${ }^{7}$ VÁZQUEZ, Luis: "Pintura y escultura del Convento Grande de la Merced de Sevilla en 1730", Estudios, 200-201, 1998, pp. 191-208 (la mención al San José de Gijón en p. 204). Dichas copias son transcritas, la primera de manera extractada y la segunda íntegramente, por QUILES GARCÍA, Fernando y CANO RIVERO, Ignacio: Bernardo Lorente Germán y la pintura sevillana de su tiempo (1680-1759). Madrid, 2006, pp. 299-303. Esa misma información de la Memoria la utilizó Ceán Bermúdez cuando publicó en su Diccionario la sucinta biografía de Francisco Ruiz Gixón, aunque al adjudicarle la "estatua de S. Josef sobre un trono de ángeles trabajada por él", elude su ubicación en el altar de la Resurrección de Murillo. CEÁN BERMÚDEZ, Juan Agustín: Diccionario histórico de los más ilustres profesores de las Bellas Artes en España. T. IV. Madrid, 1800, p. 283. Lo mismo aconteció con MATUTE Y GAVIRIA, Justino: "Adiciones y correcciones de D. Justino Matute al tomo IX, del Viaje de España de D. Antonio Ponz", Archivo Hispalense, T. III, 1887, p. 378.

8 VÁZQUEZ, Luis: "Pintura y escultura del Convento Grande de la Merced de Sevilla en 1730", op. cit., p. 204.

9 VALDIVIESO, Enrique: Murillo. Catálogo razonado de pinturas. Madrid, 2010, pp. 73 y 306.

10 CUÉLlar CONTRERAS, Francisco de P.: "Traslado de Retablo y donación de sitio para otro en la Capilla de la Cofradía del Museo. Año 1698", Boletín de las Cofradías de Sevilla, 229, 1978, pp. 11-13. 
a aquella imagen de San José, que fray Pedro Vázquez consigna como obra de Gijón, advirtiendo "que está sobre un Trono de Ángeles"; y he aquí que, sorpresivamente, la base de la escultura que ahora reclama nuestro interés puede considerarse que, en buena medida, responde a esa descripción, pues su pie derecho, el que está más retrasado, reposa sobre una bola del mundo, mientras que el izquierdo se adelanta plantando la suela de su sandalia sobre un cúmulo de nubes tachonado por tres lozanas cabezas aladas de ángeles niños -muy en la pauta de Gijón, aquí con los ojos tallados y pintados sobre la madera-, configurando una suerte de San José en Gloria o de Apoteosis de San José ${ }^{11}$ que lo sitúa en un plano celestial desde donde el custodio del redentor ve prolongado el privilegio del que gozó en la tierra de poder tener entre sus brazos al Niño Jesús, actuando desde allí como intercesor del orbe: "Porque los demás bienaventurados, como siervos del Rey Eterno, solamente pueden interceder por nosotros, interponiendo sus méritos, por modo de suplicación, para que Dios nos oyga; pero San Joseph, como tan emparentado en la representación de sus gloriosos títulos con el Rey, y Señor universal, tiene en el Reyno del Cielo Dignidad Real, en alguna manera autoritativa, para alcançar de Christo nuestro Señor, como Padre legal, y putativo suyo, y legítimo Esposo de su Madre, qualquiera cosa que le pidiere", según lo afirma el carmelita descalzo fray José de Jesús María en $1698^{12}$.

Estimo que, por todo lo expuesto, el San José que es propiedad de la Joyería Casa Ruiz, en Sevilla, puede pasar, con suficientes garantías, a engrosar el catálogo razonado de obras del escultor Francisco Antonio Gijón, como una atribución sólidamente formulada y una propuesta de datación en torno a 1685-1700.

Pero no quiero concluir estas líneas sin detenerme en unas palabras que fray Pedro Vázquez dejó escritas en 1730 en su referido memorial artístico del convento hispalense de la Merced, cuando al enumerar el elenco de imágenes de Gijón en la capilla del Cristo de la Expiración, nos comenta a propósito de este escultor que era "bien conocido por sus buenas y arrogantes obras. Murió en la flor de su edad"'13. Precioso testimonio sobre el que, hasta ahora, nadie había reparado. Téngase en cuenta que fray Pedro había profesado en dicho cenobio sevillano el 4 de

11 Tema iconográfico inusual, pero no completamente desconocido para el arte barroco español, como vendría a demostrarlo, por ejemplo, el dibujo de Antonio García Reinoso (c. 1623-1677) que se conserva en la Biblioteca Nacional de España. Cfr. PÉREZ SÁNCHEZ, Alfonso E.: Historia del dibujo en España: de la Edad Media a Goya. Madrid, 1986, p. 312. Una reciente compilación de la iconografía josefina en el arte español la ofrece DE ARRIBA CANTERO, Sandra: Arte e Iconografía de San José en España. Valladolid, 2013.

12 JOSÉ DE JESÚS MARÍA, Fray: Historia de la vida y excelencias de la Sacratíssima Virgen María Nuestra Señora. Donde se tratan muchas de su virginal esposo el Patriarca S. Ioseph. Barcelona, 1698, p. 385.

13 VÁZQUEZ, Luis: "Pintura y escultura del Convento Grande de la Merced de Sevilla en 1730", op. cit., p. 204. 
octubre de 1679 y que, por consiguiente, pudo muy bien haber conocido y tratado personalmente a Francisco Antonio Gijón, al menos cuando este trabajó para la aludida cofradía penitencial de la Expiración, radicada como sabemos dentro del propio recinto conventual. Se hace eco de la extendida fama del artista ("bien conocido") y de la positiva valoración coetánea de sus obras, calificadas de "buenas y arrogantes", entendiendo este último término en su acepción de valiente, alentado y brioso ${ }^{14}$, lo que casa a la perfección con el perceptible barroquismo que alienta sus formas escultóricas. Y termina revelándonos que Gijón "murió en la flor de su edad". Se ha especulado mucho con la fecha del fallecimiento del escultor, aceptándose a veces la de 1720 propuesta por Justino Matute para ese Bernardo Gijón que Ceán Bermúdez había considerado sobrino y discípulo de Francisco Antonio, aunque posteriormente se haya negado la existencia del primero de ellos, pensándose que su personalidad se habría confundido con la del segundo ${ }^{15}$. Mas es lo cierto que la última fecha que hasta ahora tenemos certificada de Francisco Antonio Gijón nos remite al 8 de julio de $1705^{16}$, perdiéndose después todo rastro documental suyo, quizás porque aconteciera su muerte en un plazo de tiempo presumiblemente cercano. Habrá que reconocer que la expresión de fray Pedro Vázquez se compadece mejor con esta última suposición, y que el óbito de Gijón en torno a los 52 años, más que a los 67 si su defunción hubiera sucedido en 1720, supondría que murió, en efecto, "en la flor de su edad".

Fecha de recepción: 15 de septiembre de 2015.

Fecha de aceptación: 20 de noviembre de 2015.

${ }^{14}$ Real Academia Española, Diccionario de la lengua castellana... Madrid, 1726, p. 417.

${ }^{15}$ CEÁN BERMÚDEZ, Juan Agustín: Diccionario histórico de los más ilustres profesores de las Bellas Artes en España. T. II. Madrid, 1800, p. 199. MATUTE Y GAVIRIA, Justino: Hijos de Sevilla señalados en santidad, letras, armas, artes o dignidad. Tomo I. Sevilla, 1886, p. 138. Matute ofrece la noticia de la muerte de Bernardo Gijón en la collación de Santa Marina y su enterramiento en dicha parroquia, "por los años de 1720". Es lo que repite Antonio Gómez Aceves en sus papeles manuscritos guardados en la Real Sociedad Económica Sevillana de Amigos del País, de donde lo recoge GESTOSO Y PÉREZ, José: Ensayo de un diccionario de los artífices que florecieron en Sevilla desde el siglo XIII al XVIII inclusive. Tomo I. Sevilla, 1899, p. 232. El profesor Bernales Ballesteros se plantea la inexistencia de Bernardo Gijón y su confusión historiográfica con Francisco Antonio Gijón, con quien debería, a su juicio, identificarse. BERNALES BALLESTEROS, Jorge: Francisco Antonio Gijón, op. cit., pp. 43-45.

${ }^{16}$ CARO QUESADA, María Salud: Noticias de Escultura (1700-1720). Sevilla, 1992, p. 104. Se trata de una escritura notarial por la que Gijón recibe en alquiler una casa en la que vivía, situada en la plaza de los Marteles, perteneciente a la collación de Santa Lucía, por período de un año y una renta mensual de 30 reales. 


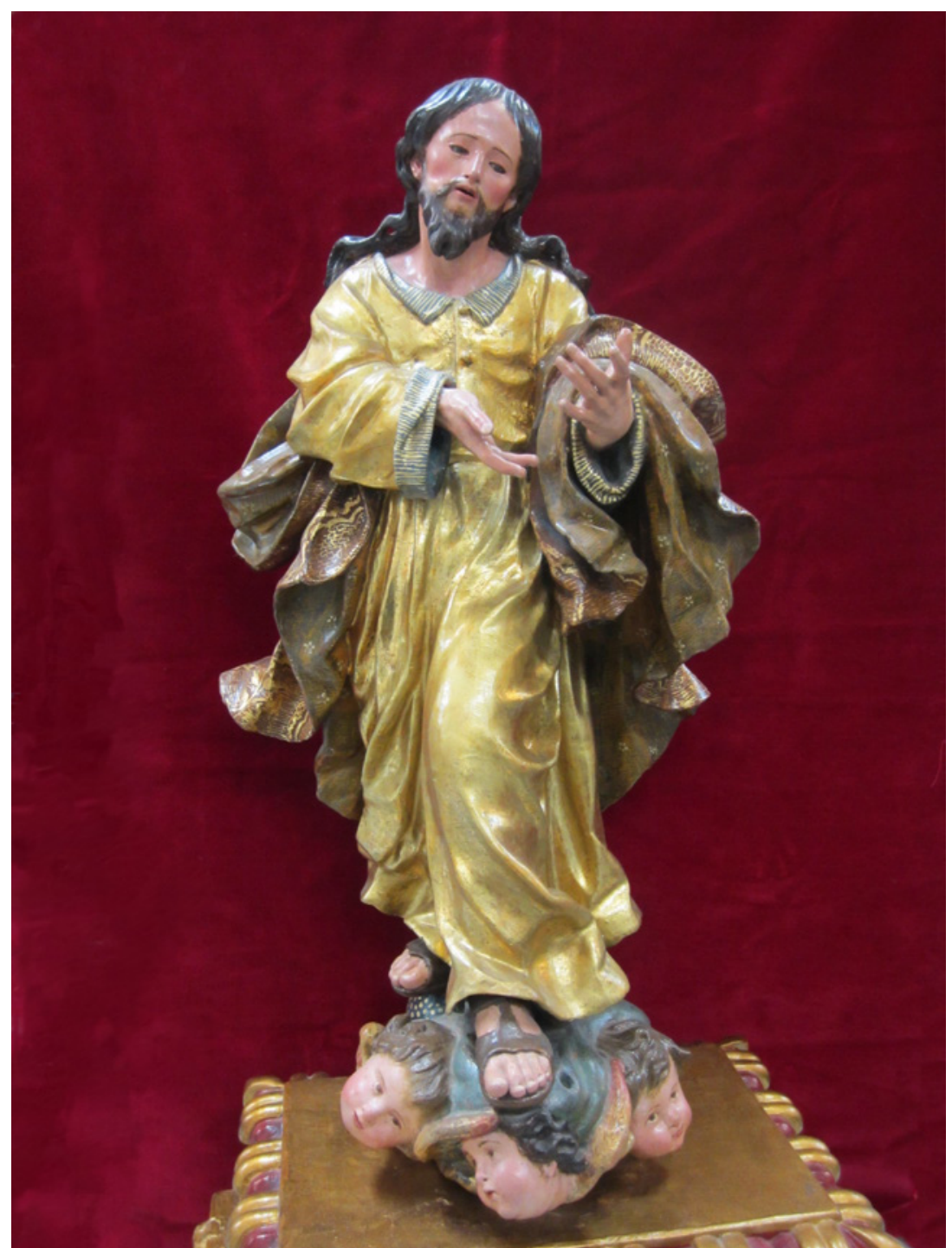

Figura 1. Francisco Antonio Gijón (atribución). San José. Hacia 1685-1700. Joyería Casa Ruiz, Sevilla. 


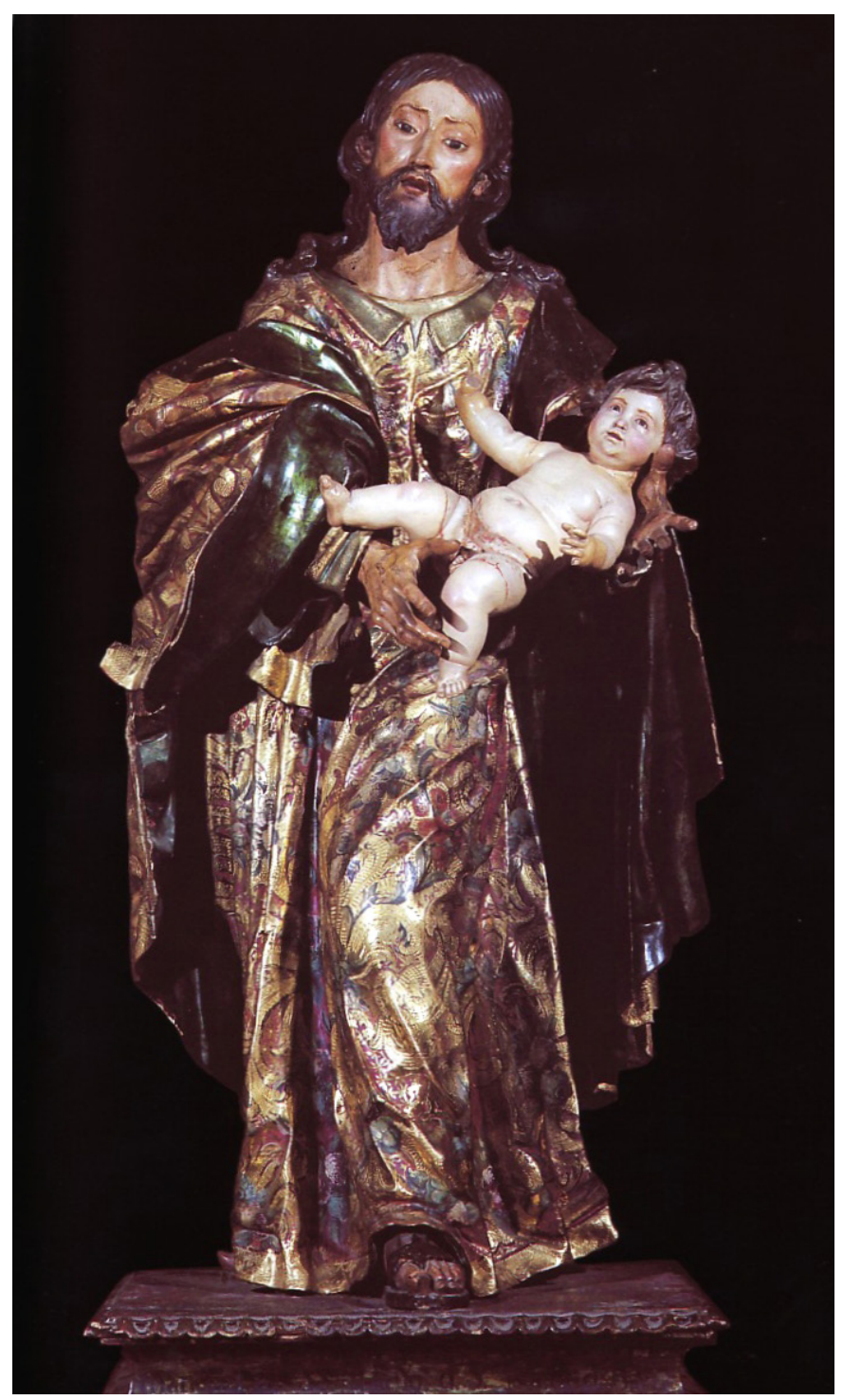

Figura 2. Francisco Antonio Gijón. San José con el Niño Jesús. 1678. Parroquia de San Nicolás, Sevilla. 

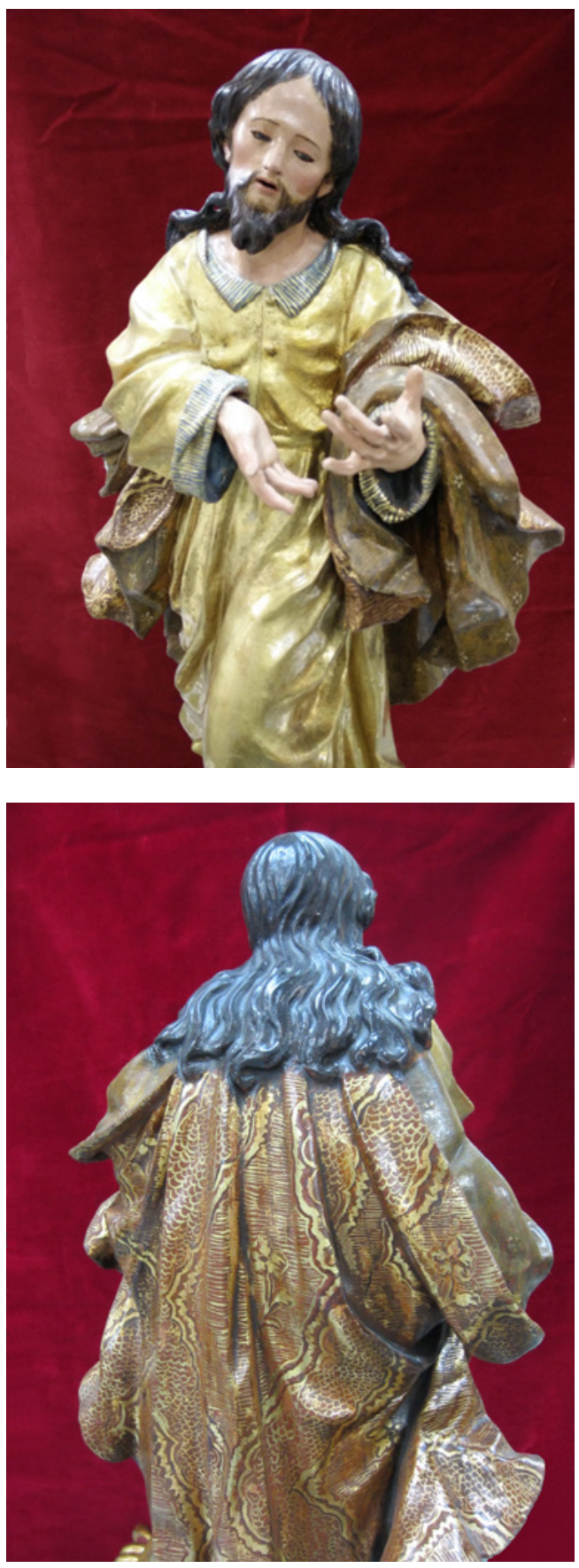

Figura 3. Francisco Antonio Gijón (atribución). San José (detalle).
Figura 4. Francisco Antonio Gijón (atribución). San José (detalle). 
Figura 5. Francisco Antonio Gijón (atribución). San José (detalle).

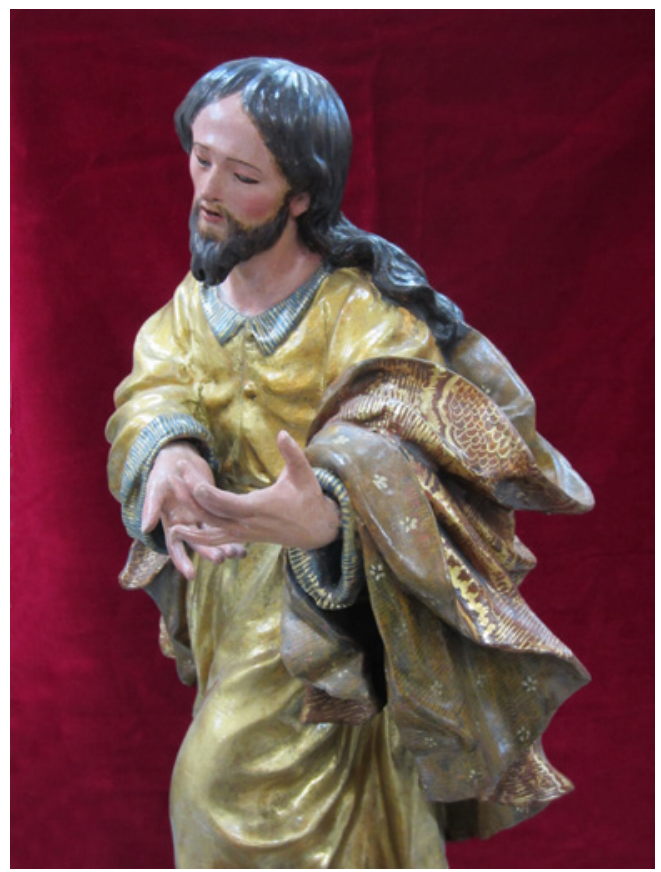

Figura 6. Francisco Antonio Gijón (atribución). San José (cabeza).

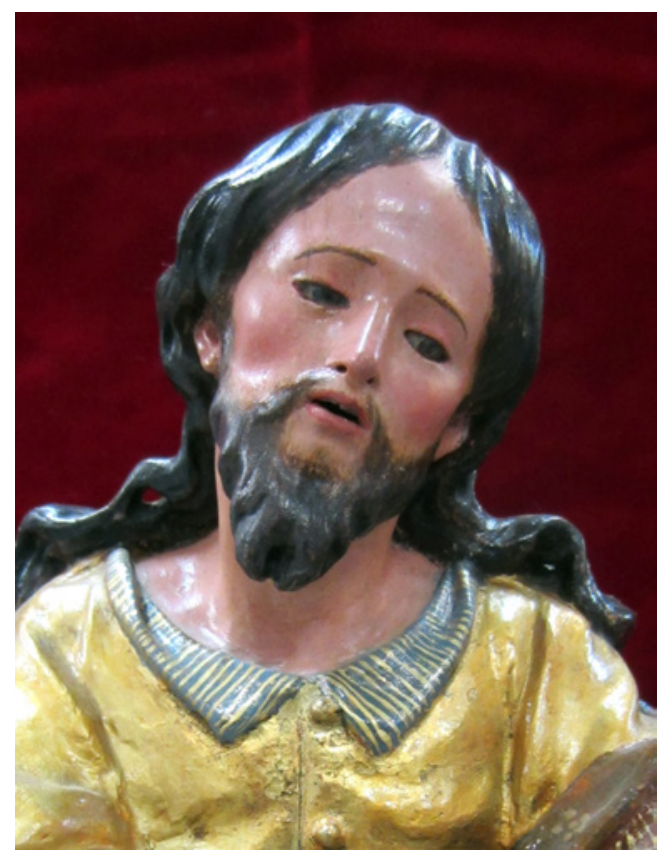

LABORATORIO DE ARTE 28 (2016), pp. 179-190, ISSN 1130-5762 e-ISSN 2253-8305 - DOI http://dx.doi.org/10.12795/LA.2006.i.01.10 


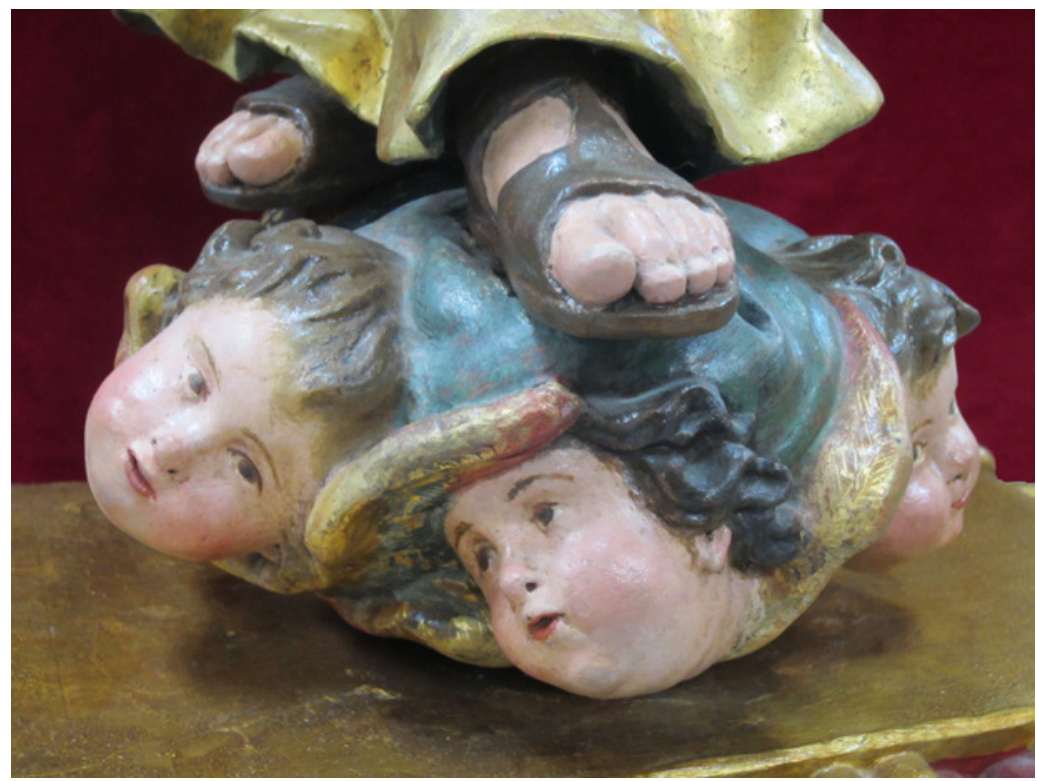

Figura 7. Francisco Antonio Gijón (atribución). San José (frente de la peana).

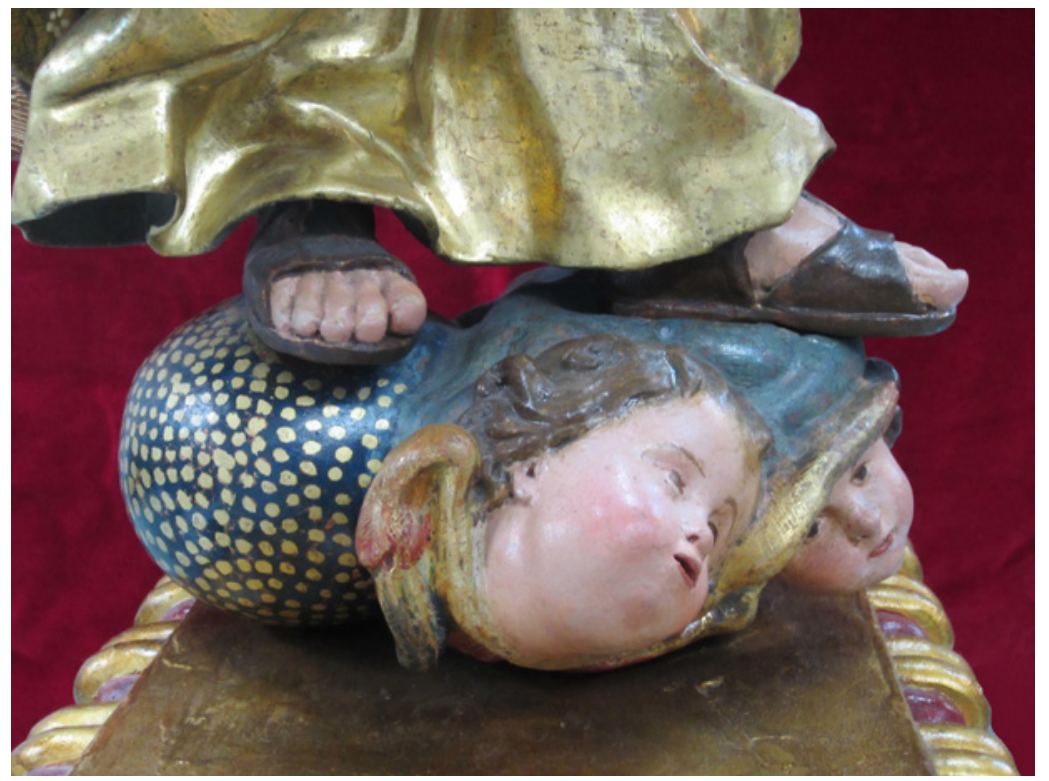

Figura 8. Francisco Antonio Gijón (atribución). San José (lateral de la peana).

LABORATORIO DE ARTE 28 (2016), pp. 179-190, ISSN 1130-5762

e-ISSN 2253-8305 - DOI http://dx.doi.org/10.12795/LA.2006.i.01.10 